\title{
Proceeding
}

Supplementary Issue: Spring Conferences of Sports Science. Costa Blanca Sports Science Events, 14-15 June 2019. Alicante, Spain.

\section{The role of the extra physical activity on memory storage and psychosocial features}

\author{
GABRIELE RUSSO ${ }^{1}$, FEDERICO NIGRO1 ${ }^{1}$, GAETANO RAIOLA², ANDREA CECILIANI ${ }^{1}$ \\ ${ }^{1}$ Department for Life Quality Studies, University of Bologna, Italy \\ ${ }^{2}$ Department of Human, Philosophical and Educational Science, University of Salerno, Italy
}

\begin{abstract}
The present research investigated the role of the physical activity on cognitive functions and psychosocial characteristics. Pre-adolescent children of a middle School of Rimini participated to extra physical activities (EPA) organised by the school. They performed a Free Recall memory Test (Nielson, Radtke \& Jensen, 1996) and filled the self-esteem questionnaire (Rosenberg, 1965) and their results were compared with a group of students that did not performed the activity proposed (non-EPA). Moreover, to control the level of physical activity of the sample, participants filled the International activity questionnaire. The results showed that the students who participated to the extra physical activities had high self-esteem compared to the nonEPA group, while no differences between the groups emerged from the Free Recall Memory test. Keywords: Physical fitness; Self-esteem; Cognitive functions; Physical education.
\end{abstract}

\section{Cite this article as:}

Russo, G., Nigro, F., Raiola, G., \& Ceciliani, A. (2019). The role of the extra physical activity on memory storage and psychosocial features. Journal of Human Sport and Exercise, 14(4proc), S948-S956. doi:https://doi.org/10.14198/ihse.2019.14.Proc4.57

Corresponding author. Department for Life Quality Studies, University of Bologna, Italy. https://orcid.org/0000-0002-7779-6225 E-mail: russo.gabriele@gmail.com

Supplementary Issue: Spring Conferences of Sports Science. Costa Blanca Sports Science Events, 14-15 June 2019. Alicante, Spain.

JOURNAL OF HUMAN SPORT \& EXERCISE ISSN 1988-5202

(c) Faculty of Education. University of Alicante

doi:10.14198/jhse.2019.14.Proc4.57

S948 | 2019| Proc4 | VOLUME 14

C 2019 University of Alicante 


\section{INTRODUCTION}

In the western world, the lack of physical activity in every phase of our lives is one of the most important problem that we have to face (Colley, Garriguet, Janssen, Clarke \& Tremblay, 2011; D'Isanto, Manna \& Altavilla, 2017; Gurnani, Birken \& Hamilton, 2015; WHO, 2015). The worrisome data are even more relevant for what concern children and adolescent where the time spent for the physical activities is very little and it is decreasing through the years (Berringan D. \& Masse, 2008; Dallolio, Ceciliani, Sanna, Garulli \& Leoni, 2016; Ding, Sallis \& Kerr, 2011; Hill \& Peters, 1998; Holt, Hill, Lee \& Millar, 2013; WHO, 2015).

The high level of sedentary (e.g. watching TV; Biddle \& Asare, 2011) combined to the poor healthy life (e.g. the junk food intake; Kumanyika, 2008) can lead to the high probability, in adulthood, to develop metabolic diseases (Penedo \& Dahn, 2005), such as obesity and cardiovascular diseases (Zhu, Jacobs, Schreiner, Yaffe, Launer, 2014; Wannamethee \& Shaper, 2001), as well as can lead to a decrement of the mental health (Biddle \& Asare, 2011). Indeed, a large amount of research indicated that the physical activity can have an important role in reducing the incidence of these diseases suggesting its promotion across all life (Altavilla, D'Elia \& Raiola, 2018). Moreover, beside physiological benefits, it has been observed that physical activity may have positive effects in both childhood and adulthood on cognitive functions such as attention and concentration abilities as well as on psychosocial characteristics such as self-esteem and self-efficacy (Biddle \& Asare, 2011; FOX, 2003; Valentini, Riccardi, Raiola \& Federici, 2018).

For these reasons, great efforts from the institutions are involved in the improvement of both the amount and the quality of the physical activity throughout the life span and especially in childhood.

In order to support these hypotheses, much research tried to shed a light on how the physical activity can affect the cognitive functions and how they can be improved. The findings, in general, showed that some cognitive functions such as the attentional ones are more developed in children that are more physical active compared to the less ones even if, according to Biddle and Asare (2011), the results are not strong and the relations are small and not entirely consistent. Furthermore, the results on memory skills are quite controversial (Sibley \& Etnier, 2003) and only some research (e.g. Pesce, Crova, Cereatti, Casella \& Bellucci, 2009) were able to find a positive relation between physical activity and memory performance.

Notwithstanding the increment of the time involved for the physical activity is not negatively related to the academic performance (Shepard, 1998). For instance, only some investigations were able to show better memory skills for the high physical active children compared to the sedentary ones (Niederer, Kriemler, Gut, Hartmann, Schindler, Barral et al., 2011).

The present research tried to shed a light on the ambiguous interaction between memory skills and physical activity in order to understand whether the physical activity can produce a positive effect on the memory abilities. Moreover, we tested participants' self-esteem (RSES - Rosenberg, 1965) in order to understand whether there was an effect of physical activity on the self-esteem and whether the self-esteem had a role on the memory performance.

Specifically, we tested a group of students who took part to some different extra physical activities (EPA group) organised by the school and carried out in the after school. Data were matched with a control group of students that did not take part to any extra activity (non-EPA group). 
In order to control whether there were differences in the level of physical activity of the students, the International Physical Activity Questionnaire for Children (IPAQ-C, Kowalski, Crocker \& Donen, 2004) was filled by each participant.

On the basis of the premises, we hypothesised that the students that participated to the EPA should have high reported physical activity compared to the non-EPA students as well as high self-esteem for EPA group than non-EPA students. Moreover, we assumed that the students that participated to the EPA should perform the memory task better than the participants that did not take part to the EPA.

\section{METHODS}

\section{Participants}

Students of a middle school of Rimini participated in the experiment. In particular, they were 34 (19 females and 15 males) with the age of $12.77 \pm 0.69$ y.o. They had normal or corrected vision.

Participants were divided in two groups, EPA (17 students) and non-EPA (24 students) groups. Moreover, in order to test the psychosocial characteristics, participants were divided in two groups according to their selfesteem. Specifically, the sample was divided below the median (low self-esteem group) and over the median (high self-esteem group).

The study obtained the approval by the ethic committee from - the Bioethics committee of the University of Bologna. Parents and pre-adolescent were informed about the experiment and filled the informed consent.

\section{Extra Physical Activity}

The EPA consisted in three different sport activities such as frisbee, dancing and a multisport program. Students participated at the sport programme, from November to May, twice a week for 2 hours. The activities were not monitored with any devices such as heart rate monitor and/or accelerometer. Questionnaires and memory tasks administered at the end of the School (i.e. end of May).

\section{Questionnaires}

IPAQ-C (Kowalski et al., 2004) and RSES (Rosenberg, 1965) questionnaires were administered to all students. IPAQ-C (Kowalski et al., 2004) consisted in 9 questions that evaluated the physical activity performed in the previous week.

RSES instead, consisted in 10 questions were participants had to respond to a 4 Likert scale about their selfesteem.

\section{Free-recall Memory test}

Following the guideline of Pesce and colleagues (2010) and Cole and Tomporowsky (2008) we developed the Free Recall Memory test (FRMT - Nielson, Radtke \& Jensen, 1996). We selected, in accordance to the imaginable and concreteness index, 156 words from the list of word of Paivio and collaborators (1969). Specifically, all the words had an index over 6.40 for both the parameters. Through MATLAB software (MathWorks, v. 2018a), we performed a randomization of the words and we selected the firsts 20 words of the list. The experiment was programmed in Open Sesame (www.cogscie.nl, Mathot, Schreij \& Theeuwes, 2012) and they were projected on the Interactive Whiteboard. The words were black coloured on a white screen. 


\section{Procedure}

Questionnaires were filled during the class hours before the Free-recall Memory Test. The FRMT was performed in the classroom and the words were projected on the screen of the Interactive Whiteboard. Each word was projected for 5 seconds for a total of 200 seconds. After their presentation, students waited 100 seconds before to start to write down as many words as they remembered. After 100 seconds, students had two minutes to write down the words on a white paper.

Students were sitting at variable distance; however, the height of the letters $(10 \mathrm{~cm})$ was adequately for every student. Moreover, a series of 5 words were projected in order to explain the task and check whether the all the participants were able to correctly see the words. The words were randomly presented, and after 100 seconds of that the last word was presented the students could write down the words (immediate recall) on a blank paper and after 12 minutes (delayed recall), in another blank paper. The blank papers were provided by the researchers/teachers. Participants had to write down as many words as possible within 120 seconds. For each correct word reported on the blank paper we assigned 1 point, also, the words with plural and grammar mistake.

\section{Data analysis}

Statistical analysis was conducted with R Studio software (version: 1.1.463).

A liner regression analysis was involved to examine whether there were differences between the EPA and non-EPA groups and whether there was an interaction between the self-esteem and on sex in the amount of physical activity self-reported.

Due to the strong correlation between immediate Free Recall Memory test and delayed Free Recall Memory test $(R=0.70, p<.000)$ instead, MANOVA analysis was performed to evaluate the memory of the students. The independent variables were EPA (EPA VS non-EPA), self-esteem (High VS Low) and sex (Males VS Females).

\section{RESULTS}

\section{IPAQ-C and Self-esteem questionnaires}

IPAQ-C questionnaire showed a significance for the single factor $\operatorname{EPA}(F(1,37)=9.88, p=.003)$ where EPA group reported to be more active than non-EPA group ( $3.11 \pm 0.69$ VS $2.50 \pm 0.67)$; and Self-esteem ( $F(1$, $37)=5.70, p=.022)$ where high self-esteem participants reported to be more active compared with low selfesteem students (3.06 \pm .45 VS $2.45 \pm .55)$; and a trend to significance for $\operatorname{sex}(F(1,37)=3.20, p=.081)$ where the males reported to be more active than females $(2.95 \pm 0.77$ VS $2.56 \pm 0.67)$.

\section{Free recall memory task}

Assumption of normality (Shapiro test) were verified for both immediate and delayed memory tasks $(p>.05)$. MANOVA analysis showed only a significance for the single factor Self-esteem $(F(1,37)=3.70, v=0.17, p$ $=.035)$. The single factors EPA ( $p>.05)$ and $\operatorname{sex}(p>.05)$ were not significant.

The post-hoc ANOVA analysis on immediate Free Recall Memory Test did not reveal difference for the Selfesteem as well as the post-hoc analysis on delayed Free Recall Memory Test ( $p>.05)$. 


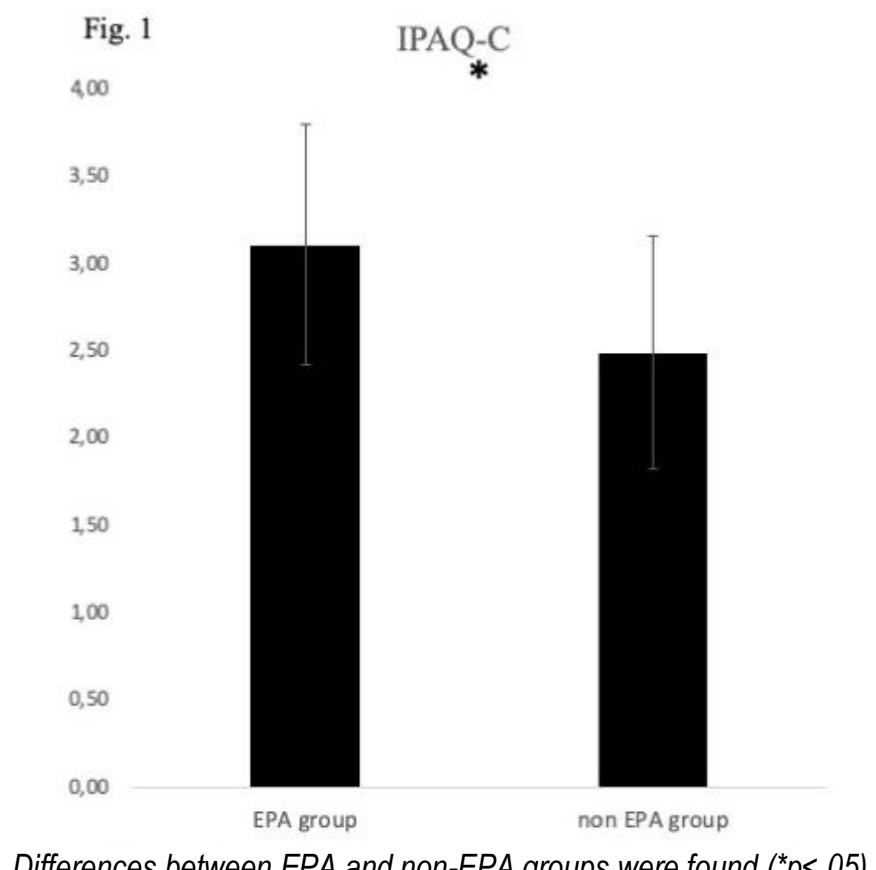

Differences between EPA and non-EPA groups were found ( $\left.{ }^{*} p<.05\right)$.

Figure 1. Shows the results of the IPA-C.

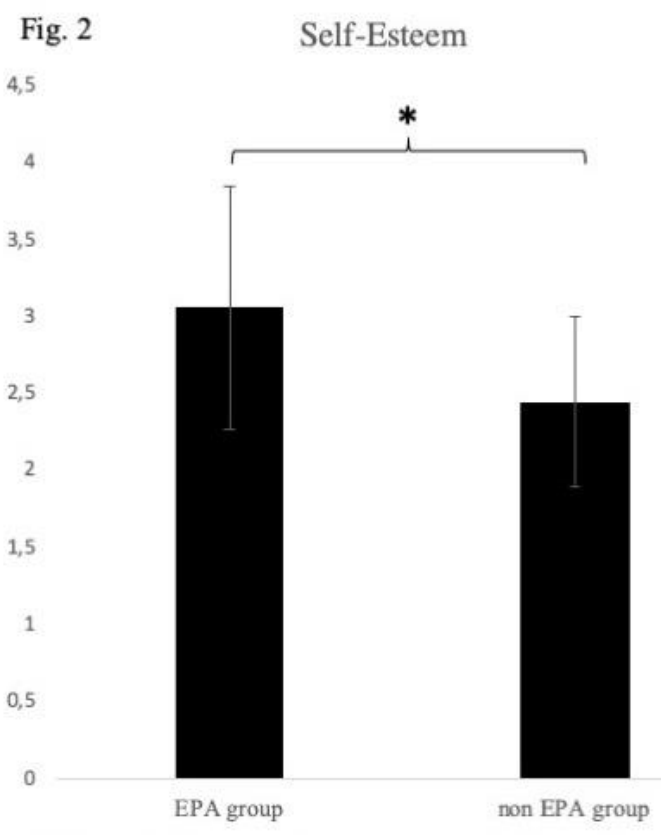

Difference between EPA and non-EPA groups were found $\left({ }^{*} p<.05\right)$.

Figure 2. Shows the results of the Self-esteem questionnaire. 

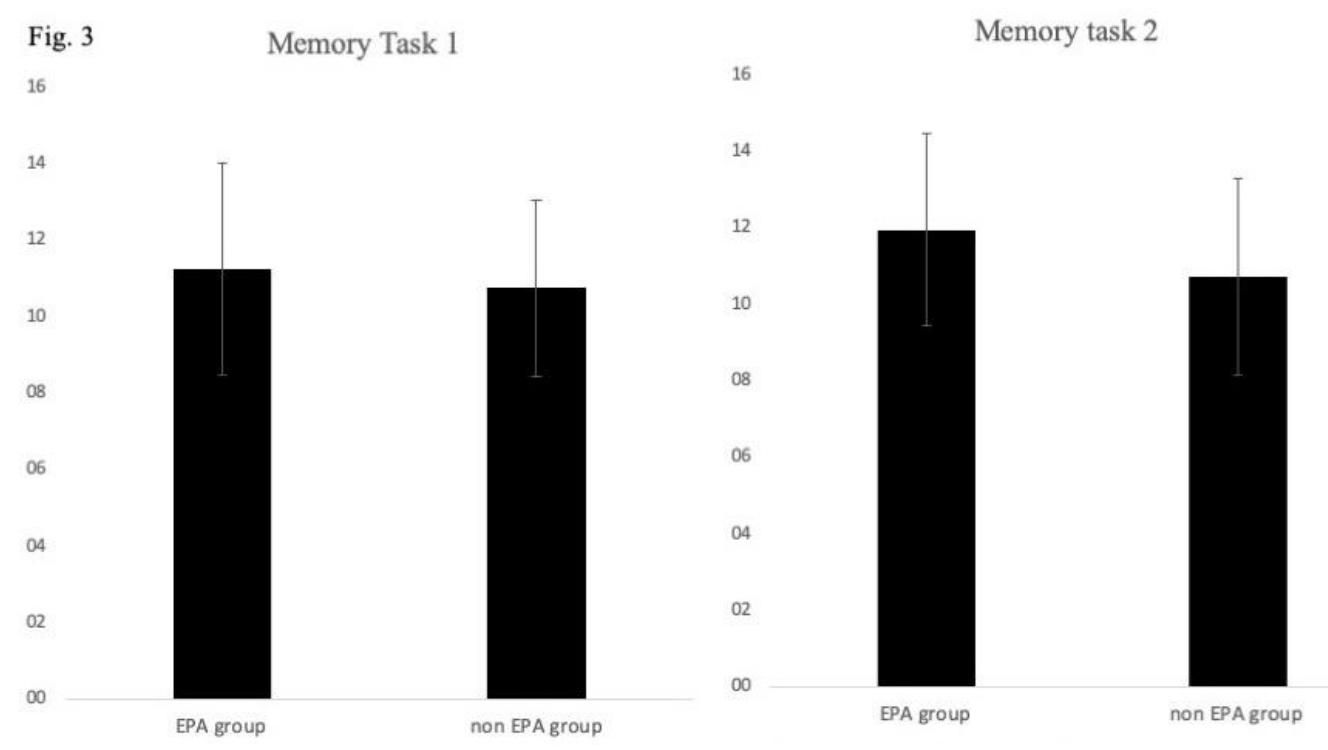

No difference from the two groups in both immediate and delayed recall memory task emerged ( $p>05)$

Figure 3. Shows the performance of the EPA and non-EPA group on Free Recall Memory Task.

\section{DISCUSSION}

The present research tried to understand whether the students that participated to an EPA program have better memory skills compared to the pre-adolescent that did not take part the activity. In order to control how much activity the two groups carried out, they filled the IPAQ-C (Kowalski et al., 2004) questionnaire. It revealed that EPA group was more active than non-EPA. Moreover, an effect of self-esteem was found where the students who participated at EPA had a high self-esteem compared to the non-EPA group. These results are in line with some previous research (Calfas \& Taylor, 1994), where more active participants had high selfesteem than less physically active students (Biddle \& Asare, 2011; Yu, Chan, Cheng, Sung \& Hau, 2006; Strauss et al., 2001). In this sample, in contrast to some previous research (Pate, Mclver, Dowda, Brown \& Addy, 2008; Strauss, Rodzilsky, Burack \& Colin, 2001), we did not find difference between males and females.

For what concern the memory skills, we hypothesised that the students that took part to extra physical activities organised by the school should show better cognitive skills.

The majority of the results on the relation of physical activity and cognitive functions such as attentional processes and concentration, showed a positive relation even if a general inconsistency of data were found (Biddle \& Asare, 2011). These results affect also memory performance, for instance some research showed a positive effect of physical activity (Pesce et al., 2009) while other no (Sibley \& Etnier, 2003). Thus, further investigations should be necessary to totally understand the phenomena and understand the possible effect of the physical activity on the memory skills..

The results of our experiment, in this sample, were not able to find differences between the EPA and nonEPA groups in the immediate and delayed Free Recall Memory test. Consequently, we were not able to provide evidences that the physical activity had a role on cognitive functions related to memory for the list of words involved in the task. 
There may be several reasons that could explain these results. One of them could be the sample size where only 17 students took part to EPA program. Another one could be due to the extra physical activity proposed. For example, according to Best (2010) the type (e.g. aerobic, endurance and/or team sports) as well as the intensity of the physical activity can affect the cognitive functions differently and we were not able to analyse them separately due to some limitations such as the low sample size.

Lastly, as the majority of the investigations carried out, this experiment was a cross-sectional study and not a longitudinal study (pre - post study). Longitudinal studies give the opportunity to better evaluate the role of the physical activity in cognitive functions. Unfortunately, we were not able to design this kind of investigation because some difficulties to organize the activities with the School were encountered.

\section{CONCLUSION}

To conclude, the present experiment provides some evidences regarding the psychosocial factors on the physical activity, but it did not provide evidence of the better memory skills of the physical active student.

Several limitations could be found in the present research, such as the sample, only 34 students participated to the investigation and other some individual characteristics such as personality characteristics were not taken into account. In future research, the sample size should be incremented, and the physical activity could be analysed through specific tests.

Moreover, as suggested by some authors, the longitudinal study design should be preferred. Again, for the future research the activity could be divided in the order to better discriminate the groups on the basis of the physical activity proposed.

\section{REFERENCES}

Altavilla, G., D'Elia, F., \& Raiola, G. (2018). A brief review of the effects of physical activity in subjects with cardiovascular disease: An interpretative key. Sport Mont, 16(3), 103-106. https://doi.org/10.26773/smj.181018

Best, J. R. (2010). Effects of physical activity on children's executive function: Contributions of experimental research on aerobic exercise. Developmental Review, 30(4), 331-351. https://doi.org/10.1016/i.dr.2010.08.001

Biddle, S. J., \& Asare, M. (2011). Physical activity and mental health in children and adolescents: a review of reviews. British journal of sports medicine, 45(11), 886-895. https://doi.org/10.1136/bjsports-2011$\underline{090185}$

Berringan D. \& Masse L. (2008). Physical Activity in the United States Measured by Accelerometer, Medicine \& Science in sports \& Exercise January, 40(1), 181-188. http://doi.org/10.1249/mss.0b013e31815a51b3

Calfas, K. J., \& Taylor, W. C. (1994). Effects of physical activity on psychological variables in adolescents. Pediatric exercise science, 6(4), 406-423. https://doi.org/10.1123/pes.6.4.406

Coles, K., \& Tomporowski, P. D. (2008). Effects of acute exercise on executive processing, short-term and long-term memory. Journal of sports sciences, 26(3), 333-344. https://doi.org/10.1080/02640410701591417

Colley, R. C., Garriguet, D., Janssen, I., Craig, C. L., Clarke, J., \& Tremblay, M. S. (2011). Physical activity of Canadian children and youth: accelerometer results from the 2007 to 2009 Canadian Health Measures Survey. Health reports, 22(1), 15. https://doi.org/10.1186/1471-2458-13-200 
Dallolio, L., Ceciliani, A., Sanna, T., Garulli, A., \& Leoni, E. (2016). Proposal for an enhanced physical education program in the primary school: Evaluation of feasibility and effectiveness in improving physical skills and fitness. Journal of Physical Activity and Health, 13(10), 1025-1034. https://doi.org/10.1123/jpah.2015-0694

Ding, D., Sallis, J. F., Kerr, J., Lee, S., \& Rosenberg, D. E. (2011). Neighborhood environment and physical activity among youth: a review. American journal of preventive medicine, 41(4), 442-455. https://doi.org/10.1016/i.amepre.2011.06.036

D'Isanto, T., Manna, A., \& Altavilla, G. (2017). Health and physical activity. Sport Science, 10(1), 100 105.

Fox, K. R. (2003). The effects of exercise on self-perceptions and self-esteem. In Physical activity and psychological well-being (pp. 100-119). Routledge.

Gurnani, M., Birken, C., \& Hamilton, J. (2015). Childhood obesity: causes, consequences, and management. Pediatric Clinics, 62(4), 821-840. https://doi.org/10.1016/i.pcl.2015.04.001

Holt, N. L., Lee, H., Millar, C. A., \& Spence, J. C. (2015). 'Eyes on where children play': A retrospective study of active free play. Children's Geographies, 13(1), 73-88. https://doi.org/10.1080/14733285.2013.828449

Hill J., O. \& Peters J., C. (1998). Environmental contributions to the obesity epidemic. Science. 280(5368). 1371-4.

Kowalski, K. C., Crocker, P. R., \& Donen, R. M. (2004). The physical activity questionnaire for older children (PAQ-C) and adolescents (PAQ-A) manual. College of Kinesiology, University of Saskatchewan, 87(1), 1-38.

Kumanyika, S. K. (2008). Environmental influences on childhood obesity: ethnic and cultural influences in context. Physiology \& behavior, 94(1), 61-70. https://doi.org/10.1016/j.physbeh.2007.11.019

Mathôt, S., Schreij, D., \& Theeuwes, J. (2012). OpenSesame: An open-source, graphical experiment builder for the social sciences. Behavior research methods, 44(2), 314-324. https://doi.org/10.3758/s13428-011-0168-7

Niederer, I., Kriemler, S., Gut, J., Hartmann, T., Schindler, C., Barral, J., \& Puder, J. J. (2011). Relationship of aerobic fitness and motor skills with memory and attention in preschoolers (Ballabeina): a cross-sectional and longitudinal study. BMC pediatrics, 11(1), 34. https://doi.org/10.1186/1471-2431-11-34

Nielson, K. A., Radtke, R. C., \& Jensen, R. A. (1996). Arousal-induced modulation of memory storage processes in humans. Neurobiology of learning and memory, 66(2), 133-142. https://doi.org/10.1006/nlme.1996.0054

Shephard, R. J. (1997). Curricular physical activity and academic performance. Pediatric exercise science, 9(2), 113-126. https://doi.org/10.1123/pes.9.2.113

Pate, R. R., Mclver, K., Dowda, M., Brown, W. H., \& Addy, C. (2008). Directly observed physical activity levels in preschool children. Journal of school health, 78(8), 438-444. https://doi.org/10.1111/j.17461561.2008.00327.x

Paivio, A., Yuille, J. C., \& Madigan, S. A. (1968). Concreteness, imagery, and meaningfulness values for 925 nouns. Journal of Experimental Psychology, 76(1, Pt.2), 1-25. https://doi.org/10.1037/h0025327

Penedo, F. J., \& Dahn, J. R. (2005). Exercise and well-being: a review of mental and physical health benefits associated with physical activity. Current opinion in psychiatry, 18(2), 189-193. https://doi.org/10.1097/00001504-200503000-00013

Pesce, C., Crova, C., Cereatti, L., Casella, R., \& Bellucci, M. (2009). Physical activity and mental performance in preadolescents: Effects of acute exercise on free-recall memory. Mental Health and Physical Activity, 2(1), 16-22. https://doi.org/10.1016/j.mhpa.2009.02.001 
Rosenberg, M. (1965). The measurement of self-esteem, Society and the adolescent self-image. Princeton, 16-36.

Sibley, B. A., \& Etnier, J. L. (2003). The relationship between physical activity and cognition in children: a meta-analysis. Pediatric exercise science, 15(3), 243-256. https://doi.org/10.1123/pes.15.3.243

Strauss, R. S., Rodzilsky, D., Burack, G., \& Colin, M. (2001). Psychosocial correlates of physical activity in healthy children. Archives of pediatrics \& adolescent medicine, 155(8), 897-902. https://doi.org/10.1001/archpedi.155.8.897

Valentini, M., Riccardi, F., Raiola, G., \& Federici, A. (2018). Educational research: motor area and relational area during children's personality development. Journal of Physical Education and Sport, $18,2157$.

Van der Borght, K., Havekes, R., Bos, T., Eggen, B. J. L., \& Van der Zee, E. A. (2007). Exercise improves memory acquisition and retrieval in the Y-maze task: Relationship with hippocampal neurogenesis. Behavioral Neuroscience, 121(2), 324-334. https://doi.org/10.1037/0735-7044.121.2.324

Wannamethee, S. G., \& Shaper, A. G. (2001). Physical activity in the prevention of cardiovascular disease. Sports medicine, 31(2), 101-114. https://doi.org/10.2165/00007256-200131020-00003

Warburton, D. E., Nicol, C. W., \& Bredin, S. S. (2006). Health benefits of physical activity: the evidence. Canadian medical association journal, 174(6), 801-809. https://doi.org/10.1503/cmaj.051351

Wijnhoven TM, van Raaij JM, Spinelli A, et al. (2014) WHO European Childhood Obesity Surveillance Initiative: body mass index and level of overweight among 6-9-year-old children from school year 2007/2008 to school year 2009/2010. BMC Public Health; 14:806. https://doi.org/10.1186/14712458-14-806

Whitmer, R. A., Gustafson, D. R., Barrett-Connor, E., Haan, M. N., Gunderson, E. P., \& Yaffe, K. (2008). Central obesity and increased risk of dementia more than three decades later.Neurology,71(14),1057-1064. https://doi.org/10.1212/01.wnl.0000306313.89165.ef

World Health Organization. Why does childhood overweight and obesity matter? (www.who.int/dietphysicalactivity/childhood_consequences/en).

Yu, C. C. W., Chan, S., Cheng, F., Sung, R. Y. T., \& Hau, K. T. (2006). Are physical activity and academic performance compatible? Academic achievement, conduct, physical activity and self-esteem of Hong Kong Chinese primary school children. Educational Studies, 32(4), 331-341. https://doi.org/10.1080/03055690600850016

Zhu, N., Jacobs, D. R., Schreiner, P. J., Yaffe, K., Bryan, N., Launer, L. J., ... \& Bouchard, C. (2014). Cardiorespiratory fitness and cognitive function in middle age: the CARDIA study. Neurology, 82(15), 1339-1346. https://doi.org/10.1212/WNL.0000000000000310

\section{(9) $(\Theta \Theta \Theta$}

This work is licensed under a Attribution-NonCommercial-NoDerivatives 4.0 International (CC BY-NC-ND 4.0). 